\title{
Soundless Revolution: \\ Comparative Analysis On How To Propel The Global Ubiquitous IT Business Market According To Changes In The World Information Technology Market Environment
}

\author{
Yangkoo Kang, (E-mail: ykang3@campus.hpu.edu), Hawaii Pacific University \\ Joseph Chunghi, Ha (E-mail: jha@hpu.edu), Hawaii Pacific University
}

\begin{abstract}
National policy and paradigm in enterprise management are also changing from "make \& sell" to "sense \& respond." A country or enterprise that makes and sells with no particular plan should fail. Countries and enterprises should sense what consumers and market demand and should respond to it quickly. Only when countries and enterprises catch the latest information and process it for application, they can expect to succeed. In this research, the researcher analyzed the research and industry trend of leading enterprises and countries such as Japan, among the United States, the European Union (EU) and the Far East Asia. Also the researcher examined trend in policy and propulsion status of enterprises in the United States. Comparative analysis on how to propel Ubiquitous Business Market in advanced enterprises in EU and Japan can be done too.
\end{abstract}

\section{INTRODUCTION}

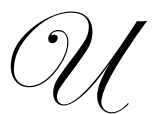

biquitous information technology (hereinafter, “Ubiquitous IT”), which appeared as a new paradigm of computerization, can be defined as an effort to make physical space intelligent with technologies such as ubiquitous computing and ubiquitous network and to connect various objects in the physical space in a network. Just like the Internet connects computers that are apart, a ubiquitous society connects lots of physical objects that exist isolated in the environment. Therefore, Ubiquitous IT means the development step of computerization that connects human, computer, objects in a network, sends and receives information in the threedimensional space.

The Ubiquitous IT is being recognized as a new strategy to build a new knowledge-based country and to enhance the country's competitive power in the information industry. Governments and enterprises of IT countries compete intensely to build a ubiquitous environment and to preoccupy related markets. Especially, the United States, Japan and European countries engage in active investment and research through a cooperative system among the industry, universities, and the government.

As digital convergence is in progress in fixed and mobile communication networks, devices and services, the word "Ubiquitous," which has been understood in the abstract, is being embodied[1-3]. Also, various projects have been developed by leading IT companies and universities. In that, they are developing a new business model and trying to preoccupy the market by testing experimental products and services. National policy and paradigm in enterprise management are also changing from "make \& sell" to "sense \& respond." A country or enterprise that makes and sells with no particular plan should fail. Countries and enterprises should sense what consumers and market demand and should respond to it quickly. Only when countries and enterprises catch the latest information and process it for application, they can expect to succeed. Therefore, governors of countries and managers of enterprises have to decide how to respond to the change in future technological environment. 
Table 1: Ubiquitous Policy Of The World

\begin{tabular}{|c|l|l|l|}
\hline & \multicolumn{1}{|c|}{ U.S.A } & \multicolumn{1}{|c|}{ Japan } & \multicolumn{1}{c|}{ Europe } \\
\hline Established Year & \multicolumn{1}{|c|}{$\mathbf{1 9 9 1}$} & \multicolumn{1}{c|}{$\mathbf{2 0 0 1}$} \\
\hline Character of Policy & $\begin{array}{l}\text { Led by private sector with the } \\
\text { financial support from } \\
\text { governmental bodies and large } \\
\text { companies }\end{array}$ & $\begin{array}{l}\text { Organizing the union composed } \\
\text { of industry, academic circles } \\
\text { and government }\end{array}$ & $\begin{array}{l}\text { Cooperation among European } \\
\text { countries led by EU }\end{array}$ \\
\hline Major Objective & $\begin{array}{l}\text { Presentation of technological } \\
\text { vision and early development of } \\
\text { application } \\
\text { (Practical strategies) }\end{array}$ & $\begin{array}{l}\text { Establishment of new } \\
\text { technology system for future } \\
\text { (Strategy for early spreading) }\end{array}$ & $\begin{array}{l}\text { Exploring to cope with the next } \\
\text { generation technology }\end{array}$ \\
\hline
\end{tabular}

\section{PURPOSE AND SIGNIFICANCE OF STUDY}

From now on, the research examines the future images of each sector including government, enterprise, and public sectors if the Global Ubiquitous Business Market were to be actualized. First, two visions can be suggested regarding the future image of Ubiquitous Government (U-Government).

The first vision is that future government services will be customized according to what a citizen needs, will be accessible without any delay, and will be available to citizens without the limitations of time and space. In addition, all process will be computerized. Citizens will enjoy a simple, convenient, and fast access to government services via broadband network in the future. Citizens, wherever they are, will be able to access to government services via wireless network and mobile devices[4]. Moreover, government services will become intelligent via computer sensors and chips that combine online and offline space.

The second vision is that government can save management cost by building an efficient system that will enable government employees to process their works without being at office physically or without having everyone get together at the same spot.

That is to say, teleportation service will actualize "my-office-at-anywhere" and will save time and money that have been wasted in documentation process and in arranging and hosting government meetings. Next, the future of Ubiquitous Business (U-Business) can be suggested. U-Business optimizes the production and management process by introducing information technology, especially in the areas such as B2B (business-to-business) and B2C (businessto-consumer), in producing and circulating products and services and in managing trade and stock. Products and services will be made according to individual consumer's need. Consumers will enjoy real-time services provided by U-Business. "Intelligent" products that contain computer sensor and chips in them will provide consumers with convenient and easy to use services[5].

Therefore, in production process, productivity can be maximized by using RFID (Radio Frequency Identification), such as the increase in raw material utilization rate, the increase in operating ratio, the quality improvement, the decrease in order latency, and the decrease in defective proportion[6]. Also, WMS (Warehouse Management System) can maximize efficiency by decreasing cargo-working time and loading error, increasing accuracy in warehousing and delivery, and preventing loss and robbery, as it can automatically analyze product information and position control in the whole process from warehousing to delivery. In addition to it, PLM (Product Lifecycle Management) can increase customer satisfaction and manage stock safely by managing the life cycle of product such as planning, design, production, AS and abolition. Thirdly, in the aspect of individual life (Ubiquitous Life: U-Life), the scene of knowledge-based welfare country that enjoy more convenient, safe and abundant life in intelligent objects and environment based on Ubiquitous IT technology can be drawn[7]. It is to decrease simple labor such as housework, to support convenient and comfortable life, to build social safety net such as preventing accident inherent in environment and objects with various safety devices, and to actualize Ubiquitous-based welfare society by improving the convenience for the elders and the disabled through various services that intelligent public facility provides. 
Figure 1: The Size Of International RFID Market (In Billion U.S. Dollar)

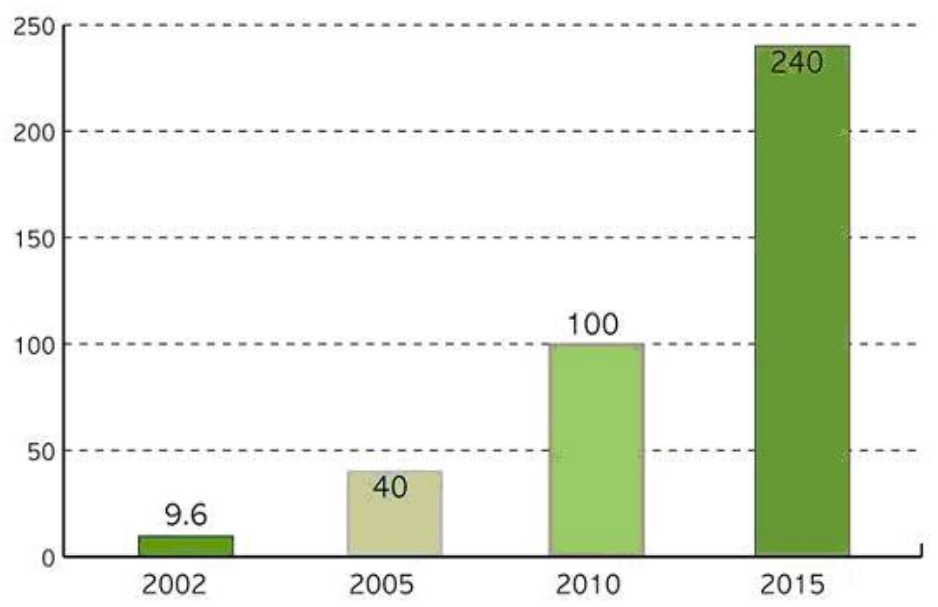

The purpose of this study is to provide a timely analysis of cases in leading IT countries, to examine global trends in constructing and propelling ubiquitous environment, and to suggest ways to propel Ubiquitous Business (UBusiness)[8]. By considering domestic and foreign trend, we will be able to find policy directions and strategies to pursue. Also, based on the study results, we can systemize future-oriented response strategies for national and business progress without falling behind to the global trend, and can be a leader in international IT business.

\section{FUTURE OF UBIQUITOUS COMPUTING: BUSINESS MODEL}

\section{Evolution Of Ubiquitous Computing By Stage}

Ubiquitous computing is developing in six stages at large. At the moment, ubiquitous computing is entering the third stage (embedded in everyday goods), and MPU, etc, is being basically embedded in electronic goods (the first stage), and portable information device is being spread (the second stage) along with the distribution of mobile phone[8][9]. Recently, the ubiquitous computing is being advanced in earnest as RFID chip, etc is being transplanted into everyday goods.

Table 2: Evolution Of Ubiquitous Computing

\begin{tabular}{|c|c|c|}
\hline Stage & Type & Description \& Example \\
\hline $1^{\text {st }}$ Stage & Intelligent device & Embedding MPU in cars, electronic devices, etc \\
\hline $2^{\text {nd }}$ Stage & Mobile device & $\begin{array}{l}\text { Expanded distribution of portable information device, such as mobile phone, PDA, } \\
\text { M/PC, etc }\end{array}$ \\
\hline $3^{\text {rd }}$ Stage & $\begin{array}{l}\text { Embedding in } \\
\text { ordinary goods }\end{array}$ & $\begin{array}{l}\text { Embedding sensors in ordinary goods, such as razor, clothes, etc - intelligent } \\
\text { ordinary goods }\end{array}$ \\
\hline $4^{\text {th }}$ Stage & Wearable device & $\begin{array}{l}\text { Eliminating problem with portability caused by computing device - making devices } \\
\text { smaller, improving UI }\end{array}$ \\
\hline $5^{\text {th }}$ Stage & $\begin{array}{c}\text { Embedding in the } \\
\text { environment }\end{array}$ & Embedding sensors and computing devices in living space \\
\hline $6^{\text {th }}$ Stage & $\begin{array}{l}\text { Ubiquitous } \\
\text { computing }\end{array}$ & $\begin{array}{l}\text { Constructing organic and seamless network among environment, objects and } \\
\text { human beings that are blended harmoniously }\end{array}$ \\
\hline
\end{tabular}




\section{Evolution Of Value System}

future.

The ubiquitous computing is expected to have five types of business categories such as followings in the

Figure 2: Value System Of Ubiquitous Computing

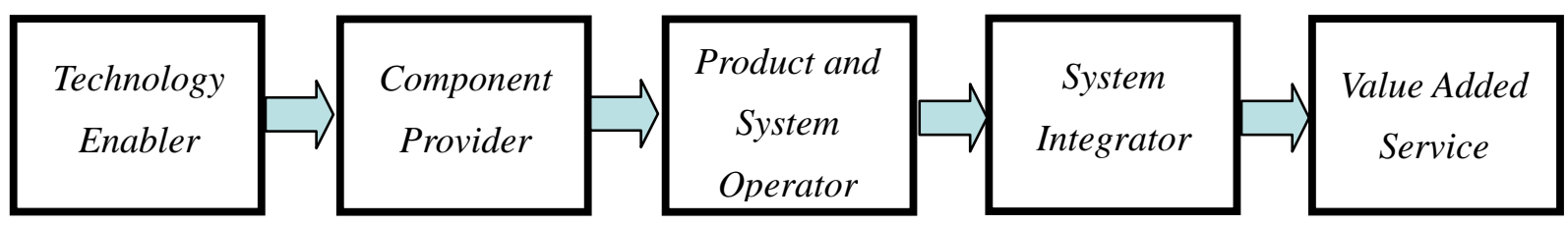

Figure 3: Prospects For Value System In The Incipient System

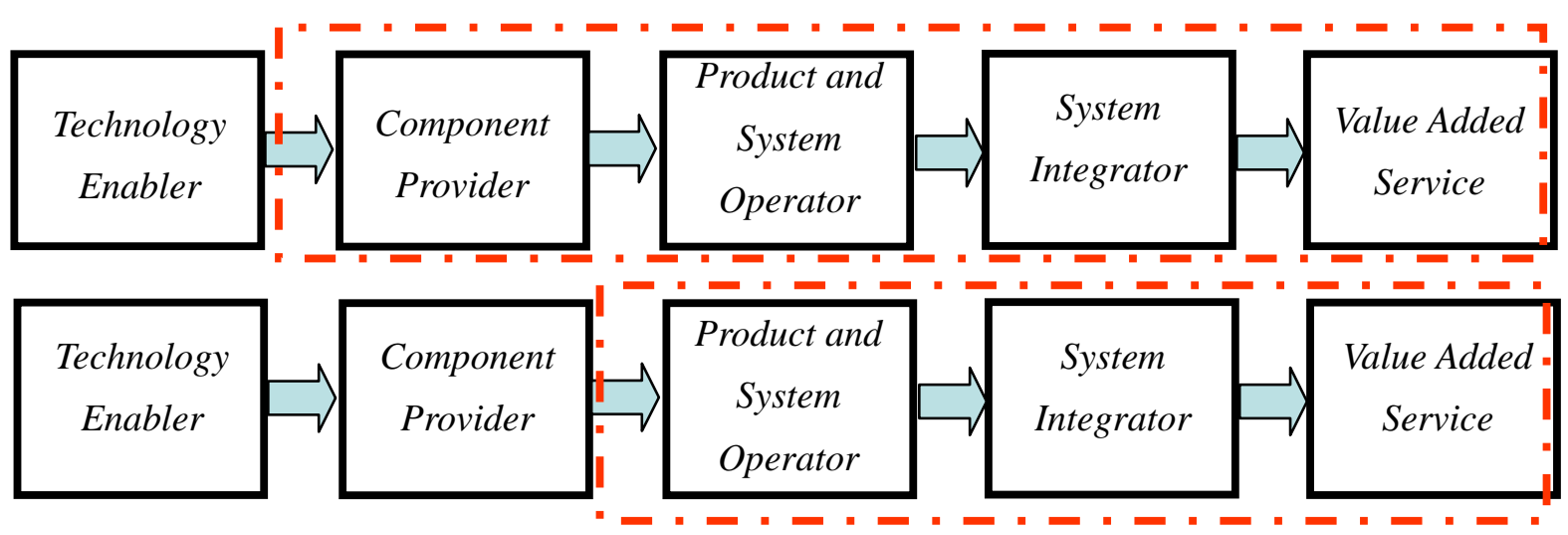

Technology Enabler

Technology enabler refers to a company organization that provides the technical standard to embody ubiquitous computing. At present, technology enabler is being operated mostly as an organization or research consortium because parties of various and complex interest are to be coordinated to embody ubiquitous computing.

For example, it includes UBID, TRON, and Auto ID Center and so on. As the competition between technologies is getting fiercer, it is expected that the emergence of companies capable of exerting exclusive influence through technology would be difficult. However, companies which will lead the technology will emerge in the field of security and certification in the long-term.

\section{Component Provider}

Component provider refers to a company which supplies components related to element technology, such as sensor, processor, network, and so on. The demand for sensor is expected to expand exponentially along with the advancement of ubiquitous computing. However, the expansion of value-added by means of sensor is expected to be a challenge, considering that the decrease in price is essential to popularize ubiquitous computing.

However, high value-added will be obtainable in case of high performance sensor which takes the de facto reign of standard in the field of special usage. In the long-term, components, etc, are provided as utility concept for 
ubiquitous computing, and the components themselves would not the business that realizes the profit, but would rather be a field that offers for free or at low price for the expansion of other field that belong to the value system.

\section{Product And System Operator}

It provides the product that performs the ubiquitous computing function. It includes the terminals devoted to ubiquitous computing or network equipment, tag reader, various computing device and the like. Mark Weiser proposed table-typed information terminal, personal portable information terminal pad and large intelligent screen and so on, for ubiquitous computing device. Besides, there is also a field where sensor module is embedded in ordinary products to perform ubiquitous computing function.

Figure 4: Direction Of Ubiquitous Computing For Device Companies

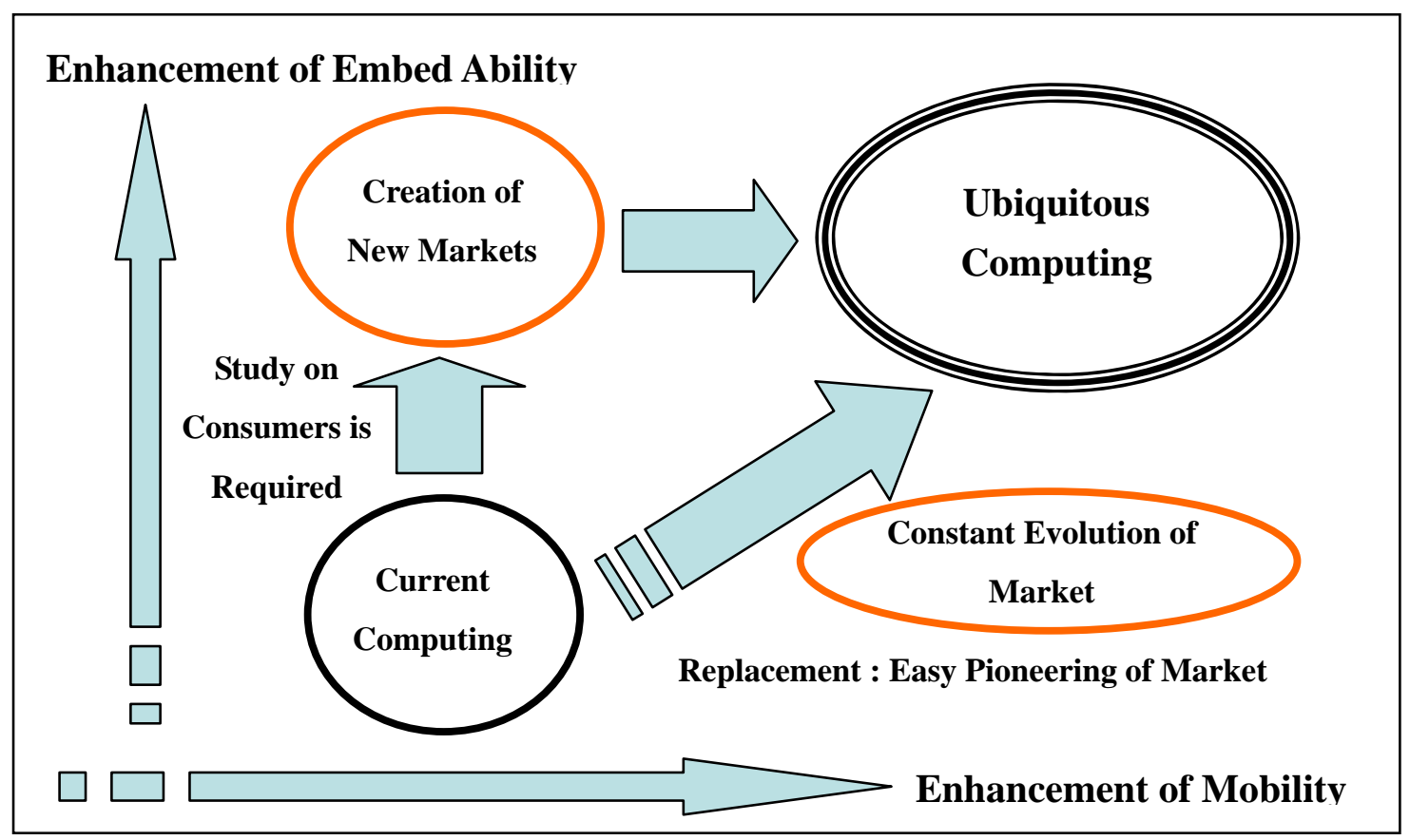

System Integrator

System Integrator (SI) is a company that connects components, products and system, etc, to integrate them into one ubiquitous computing and provide solutions. It also includes the design of consulting and system to embody ubiquitous computing that suits the environment or condition of user. Current system integrator or IT consulting companies have great advantages. Moreover, the integration of system is expected to create value-added greater than that of other field because it can be differentiated easily.

\section{Value Added Service}

It is a field that processes various forms of information which is created in ubiquitous computing environment to support the decision-making of user. It is a filed that is expected to create high value-added in ubiquitous computing in the long-term. Considering that it enables the contact with customers at ordinary times, it is a field where services that fulfill the needs of customers clearly can be nearly fully delivered and the differentiation is easy. In the long-term, professional value-added service companies are expected to emerge, depending on the industry or field of application. 
In the meantime, the specialization of value system is not very likely to be accomplished in the beginning stage of ubiquitous computing, considering the absence of vertical integration by specific company(s) in the industry as the market size is not very great and there are not many standardized product and technology.

\section{Stage Of Ubiquitous Computing Business}

System Integrator (SI) is considered to be the most lucrative field in current stage, considering that neither components nor products have formed the market that can achieve the economy of scale, and the technological field has limited value-added. At present, no large market has been formed for fields that provide value-added services. Meanwhile, SI is based on system wide consulting and so on, and has the upper hand over the product and component operators as integrator in operating businesses. The field where value-added service is provided is expected to create the greatest value-added over the long term.

It controls and processes tremendous $1^{\text {st }}$ information effectively, which is created in ubiquitous computing environment, and provide it in a way that suits the purpose of users. Moreover, companies that provide value-added services have more advantage in identifying new services because they deal with customers at ordinary times. The field which enhances 'mobility' is deemed to create higher value than the field that enhances 'embed ability' in the hardware field. Though computing with high degree of embed ability is expected to take a long time because it will ultimately transform the computing paradigm, the enhancement of mobility will make it possible to make inroads into the market while differentiating in existing markets because it is a concept of making existing devices smaller.

For example, laptops can be deemed to replace existing computers by applying the mobility to PC, and induce the proliferation of market. Therefore, technology and user technology, etc, that enhance the mobility is the core area of development, rather than the pursuit of embed ability.

\section{Task For The Long-Term Development}

Various conditions should be met to embody ubiquitous computing in earnest. Three most importantly appraised problems among those concrete details can be analyzed and summarized such as following.

\section{Technical Problem}

Technology should be standardized, core device and components should be low-priced and software technology should develop. In addition, miniaturization of hardware and low consumption of electricity are preconditions for embedding computing functions in all objects. Software and hardware which provide the inferring function similar to that of human beings need to develop over the long term, and are expected to evolve into behavior proposing and proxy stage from the stage of communication.

\section{Economic Task}

Business model and killer application problem should be reviewed in-depth as various subjects of execution need to participate. At present, killer application is not a great issue because the introduction of ubiquitous computing has clear objective and the profit and loss is also clear. However, economic issue is expected to hinder the distribution in the future. For example, one of the priorities is to address the question of who will pay for the cost of introducing ubiquitous computing environment to home. In addition, methods related to the long-term collection of initial investment cost, etc, through the introduction of service model should be explored, too.

\section{Social Task}

Strategies to overcome problems of technological complement are required, considering that the matter of primacy cannot be always perfect. Specifically, construction of social infrastructure should take precedence, such as the overhaul of legal system for privacy or information security and so on. Over the long term, the greatest problem is the problem of complexity, and complexity of information will increase exponentially as the network gets complicated. In light of that, technology needs to be developed to control the complexity of information effectively. 


\section{CHANGE IN THE ENVIRONMENT OF IT BUSINESS MARKET}

The Ubiquitous IT is being recognized as a new strategy to build a new knowledge-based country and to enhance the country's competitive power in the information industry. Governments and enterprises of IT countries compete intensely to build a ubiquitous environment and to preoccupy related markets. Especially, the United States, Japan and European countries engage in active investment and research through a cooperative system among the industry, universities, and the government[12][13].

Table 3: Comparison Of Concept Of Ubiquitous \& The Field Of Technological Development

\begin{tabular}{|l|l|l|l|}
\hline \multicolumn{1}{|c|}{ Type } & \multicolumn{1}{c|}{ USA } & \multicolumn{1}{c|}{ EU } & \multicolumn{1}{c|}{ Japan } \\
\hline Method of Expression & $\begin{array}{l}\text { Ubiquitous Computing; } \\
\text { Pervasive Computing }\end{array}$ & $\begin{array}{l}\text { Disappearing Computer; } \\
\text { Ambient Computing }\end{array}$ & Ubiquitous Network \\
\hline Service Type & $\begin{array}{l}\text { Autonomous, Service } \\
\text { Embodied by Computing } \\
\text { Device }\end{array}$ & $\begin{array}{l}\text { Autonomous Cooperation by } \\
\text { means of Information and } \\
\text { Artifacts }\end{array}$ & $\begin{array}{l}\text { Connection to the Network } \\
\text { regardless of the space, by } \\
\text { means of Tiny Chip, Smart } \\
\text { Card, Context Roaming }\end{array}$ \\
\hline $\begin{array}{l}\text { Field of Intensive } \\
\text { Development }\end{array}$ & Computer Device & Everyday Object & Network \\
\hline
\end{tabular}

\section{Trend Of Ubiquitous IT Project In The United States Of America \& Analysis On Cases}

The research project related to ubiquitous computing in the United States is mostly characterized by the systematic role-sharing and cooperation among related governmental organizations, private sector enterprises and research institutes. Though Washington emphasized networking research, such as the next generation internet (NGI) until 2000, it has expanded the investment in research and development again which are related to high performance computing since 2001. Bush Administration raised the budget allocated to ubiquitous computing to approximately \$1.867 million in 2004[12].

Furthermore, the role-sharing and cooperation among governmental organizations are very critical in preventing the overlapped investment and ensuring effective and efficient research and development. Moreover, it is considered that this systematic mutual cooperation will positively assist private sector companies in their trying to make inroads into global markets and preoccupy the global ubiquitous market that has ubiquitous environment[14].

That is because the absence of mutually connected plans or coordinating organizations are likely to cause much overlapping investment and conflict related to the work sharing in the future though governmental organizations, private sector businesses and many organizations in some European and Asian countries which are moving forward with ubiquitous computing projects have been establishing polices and planning research and development in relation to ubiquitous computing.

The United States is leading technologies in nearly all fields related to ubiquitous computing. They put emphasis on the early and partial application development and recognize Human Computer Interface (HCI) and development of standard as core element technology which is capable of naturally converging, specifically, the routine daily space and computer.

The United States aims to develop Peta-grade high performance computing technology in the hardware field as part of its strategy for technology development. Next, it is aiming to achieve the global leadership in the field of convergence technology linking the super high tech computing and super highway network by securing Peta-grade communication technology for networking. In addition, it is also moving ahead with hybrid communication technology capable of accessing via both wired and wireless network anywhere and anytime based on all-optical network, and is developing sensor network technology to connect billions of embedded sensors. The software research and development is being proceeded ahead in three fields, namely, user interface technology, component software, embedded application software development[15]. 


\section{Trend Of Ubiquitous IT Project Of European Union (EU) \& Analysis On Cases}

The 'Disappearing Computing Initiative' implemented as part of Information Society Technology (IST) of EU for two years from 2001 with the financial support of Future Technological Plan (FET) is composed of 16 independent projects. This project ultimately aims to develop information artifacts capable of computing and networking through commonly available objects embedded with small sensors, etc and build an environment that supports the daily activities of human beings through the perception of cooperative situation based on the communication between intelligent objects[12].

Europe is exploring to cope with the ubiquitous revolution by deriving the concept and technology related to the application of computer in the future through this project.

In addition, projects related to various ubiquitous computing are characterized by two things at large, which each country is moving forward under the leadership of EU.

One distinction of European ubiquitous computing project from that of U.S. is its conspicuous research on computing technology to create welfare environment for every day life, rather than the industry. In short, EU focuses on the application of information technology to support the daily lives rather than the application for business purpose.

The other distinction is its research is dedicated to the service and product development that focuses on the short distance communication among objects rather than the computing environment which concentrates to the server founded on the Internet. Like that, each country is making endeavors to implement the ubiquitous policy and project to maximize the strength in consideration of business and national conditions. EU began to drive its research and development on the ubiquitous technology in 2001 as part of IST with the financial support of FET. EU is coping with the ubiquitous revolution by implementing the under mentioned 16 projects mainly through the 'Disappearing Computing Initiative'.

\section{Trend Of Ubiquitous IT Project Of Japan \& Analysis On Cases}

In Japan, the government has spearheaded the effort at IT computerization earlier than any other Asian countries, and its ubiquitous computing is characterized by its government-led and enterprise-led projects, too.

At the moment, the Ubiquitous-related market in Japan is expanding gradually, too. The Ubiquitous-related market in Japan which was worth only 29 trillion Yen in 2003 is expected to expand into a gigantic market worth 59 trillion Yen in 2007 and 88 trillion Yen in 2010, respectively. Moreover, the Japanese government is currently driving 3 major projects for ubiquitous network, which include 'super tiny chip networking project', 'my terminal project for anything', 'anywhere-networking project'. It is moving ahead with the research and development aiming to secure related element technology by the end of 2006[12].

The policy-making in Japan has been preceded by long term review through sessions. The session which is attended by experts from private sector and government sector is committed to promoting the participation of private sector and come up with realistic policies from the stage of policy review. This system of Japan is every effective for policy-making, considering that requirements of people of various interest need to be converged to ensure a successful policy-making by companies[16-18].

U-Japan policy is more of a vision of society than the vision of technology. Japan is investing efforts at governmental level, given that it is very critical for Japan to build a well-organized ubiquitous network and create lots of examples for application in the quickest fashion[19].

The trend of study of advanced countries and global IT companies indicates clearly that the ubiquitous environment is imminent and measures to cope with that are urgently called for.

Based on that, it is important that we pave the way for our country and companies to leap into the world's top country and companies by ensuring that government and private sector companies work together and share their roles in an appropriate fashion to spearhead the construction of global ubiquitous market and induce the constant creation of demand. And strategies fore future development and direction should be crafted from various perspectives as the social environment and system should cope with such a trend[20]. 


\section{CONCLUSION AND FUTURE RESEARCH}

Ubiquitous computing means that the border between the real space and virtual space is getting blurred and meaningless. Virtual space is naturally converged into the living space through the network. As the real space called architecture built by construction companies is combined with virtual space embodied by IT companies, new ubiquitous space is created and various forms of vitality is added to it, and digital home companies are breathing various forms of vitality into it, making the lives of human beings more affluent and abundant. If the Internet linked the computers which remain isolated on desks, the Ubiquitous links countless number of physical objects which exist far away from one another in the environment. The Ubiquitous which we perceive is a quiet revolution, but its spillover effect will be really strikingly shocking.

The trend of study of advanced countries and global IT companies indicates clearly that the ubiquitous environment is imminent and measures to cope with that are urgently called for. Based on that, it is important that we pave the way for our country and companies to leap into the world's top country and companies by ensuring that government and private sector companies work together and share their roles in an appropriate fashion to spearhead the construction of global ubiquitous market and induce the constant creation of demand.

In this research, the researcher analyzed the research and industry trend of leading enterprises and countries such as Japan, among the United States, the European Union (EU) and the Far East Asia. Also the researcher examined trend in policy and propulsion status of enterprises in the United States. Comparative analysis on how to propel Ubiquitous Business Market in advanced enterprises in EU and Japan can be done too.

\section{REFERENCE}

1. Weiser, Mark, Computer Science Challenges for the Next Ten Years, (Xerox PARC) http://sandbox.xerox.com/Weiser/10year/sld001.htm

2. Weiser, Mark and John Seely Brown. Designing Calm Technology. PowerGrid Journal, v1.01, July 1996

3. $\quad$ Weiser, Mark, Hot Topic: Ubiquitous Computing, IEEE Computer, Pages 71-72, October 1993

4. Drucker, Peter, Managing in the Next Society, St. Martin's Press, 2002

5. Hunter, Richard, World without Secrets: Business, Crime, and Privacy in the Age of Ubiquitous Computing, Gartner, Inc., 2002

6. Smart-Its Friends: A Technique for users to Easily Establish Connections between Smart Art effects, http://www.inf.ethz.ch/vs/publ/papers/smf.pdf

7. $\quad$ www.ta.doc.gov/Report.htm (Vision 2020 - Transforming Education and Training Through Advanced Technologies)

8. Kim Wan-Seok, Analysis of foreign and domestic trend in Ubiquitous IT Market and industry, platform technology, LG CNS, Value creation for customers, 2003. 6.

9. Kim Dong-Hwan, Economy of Ubiquitous space and the management strategy, Telecommunications Review Vol.13 No.1, 2003. 2.

10. Kim Wan-Seok, Park Tae-Wung, Lee Seong-Guk, Kim Jeong-Guk, Baek Min-Gon, Ubiquitous Computing Strategy of IT Leaders and Hot Issues, KICS, Information and Communication Vol.20 No.5, 2003. 6.

11. http://www.ubiq.com/(Ubiquitous Home Page, Xerox Palo Alto Research Center)

12. Lee Seong-Guk, Comparative consideration of Ubiquitous Computing Strategy in US, Japan and Europe, Telecommunications Review, SK Telecom Vol.13 No.1, 2003. 2.

13. National Computerization Agency, Domestic and Overseas Trend on the Analysis of Ubiquitous Environment, 2004

14. The journal of Pervasive and Ubiquitous Computing, http://www.personal-ubicomp.com

15. The Ministry of Information-Communication, Basic plan for broadband network construction (proposal), 2004. 2.

16. Nomura Research Institute, Ubiquitous network and new-society system, The Electronic Times Internet, 2003

17. Sakamura Ken, Ubiquitous computing innovation, Donbang Media, 2002

18. Nomura Research Institute, Ubiquitous network and market creation, The Electronic Times Internet, 2002

19. IT strategy headquarters of Japan, Report of new IT strategy research society: u-Japan strategy, 2004. 5.

20. Research and study society on the future prospect of Ubiquitous Network Technology (Ministry of Internal Affairs and Communications, Japan) 


\section{NOTES}

